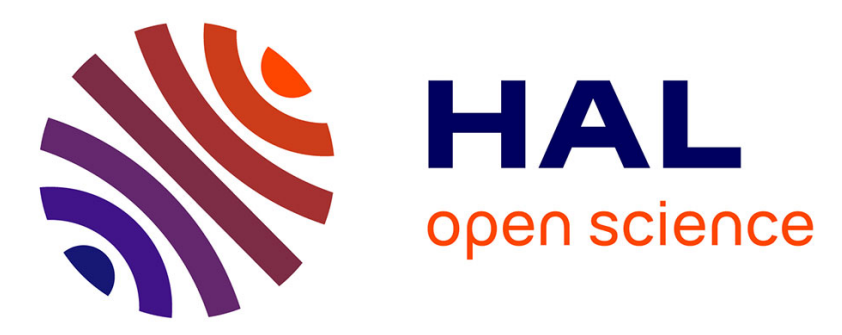

\title{
Microbiological detection of residues of ten different quinolone antibiotics and its application to artificially contaminated poultry samples
}

Godelieve Okerman, Herlinde Noppe, Vanessa Cornet, Lieven de Zutter

\section{- To cite this version:}

Godelieve Okerman, Herlinde Noppe, Vanessa Cornet, Lieven de Zutter. Microbiological detection of residues of ten different quinolone antibiotics and its application to artificially contaminated poultry samples. Food Additives and Contaminants, 2007, 24 (03), pp.252-257. 10.1080/02652030600988020 . hal-00577514

\author{
HAL Id: hal-00577514 \\ https://hal.science/hal-00577514
}

Submitted on 17 Mar 2011

HAL is a multi-disciplinary open access archive for the deposit and dissemination of scientific research documents, whether they are published or not. The documents may come from teaching and research institutions in France or abroad, or from public or private research centers.
L'archive ouverte pluridisciplinaire HAL, est destinée au dépôt et à la diffusion de documents scientifiques de niveau recherche, publiés ou non, émanant des établissements d'enseignement et de recherche français ou étrangers, des laboratoires publics ou privés. 


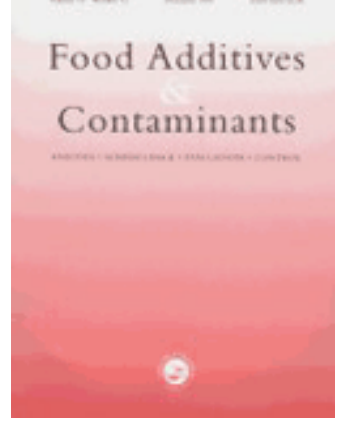

\section{Microbiological detection of residues of ten different quinolone antibiotics and its application to artificially contaminated poultry samples}

\begin{tabular}{|r|l|}
\hline Journal: & Food Additives and Contaminants \\
\hline Manuscript ID: & TFAC-2006-151.R1 \\
\hline Manuscript Type: & Original Research Paper \\
\hline Author: & 28-Aug-2006 \\
\hline Complete List of Authors: & $\begin{array}{l}\text { Okerman, Godelieve; Faculty of Veterinary Medicine, Ghent } \\
\text { University, Dep. of Veterinary Public Health and Food Safety } \\
\text { Noppe, Herlinde; Ghent University, Veterinary Public Health and } \\
\text { Food Safety } \\
\text { Cornet, Vanessa; Scientific Institute of Public Health, Food } \\
\text { Department (Chimiotherapeutic Residues) } \\
\text { De Zutter, Lieven; Faculty of Veterinary Medicine, Ghent University, } \\
\text { Veterinary Public Health and Food Safety }\end{array}$ \\
\hline Methods/Techniques: & Screening - microbial screening \\
\hline Additives/Contaminants: & $\begin{array}{l}\text { Veterinary drug residues - antibiotics, Veterinary drug residues - } \\
\text { antimicrobials, Veterinary drug residues - fluoroquinolones, } \\
\text { Veterinary drug residues - oxolinic acid }\end{array}$ \\
\hline Food Types: & \begin{tabular}{l} 
Animal, Fish and fish products, Meat \\
\hline
\end{tabular} \\
\hline
\end{tabular}

\section{SCHOLARONE ${ }^{\text {M }}$ Manuscripts}


1 Microbiological detection of residues of ten different quinolone

2 antibiotics and its application to artificially contaminated poultry

3 samples

Lieve Okerman (1)*, Herlinde Noppe (1), Vanessa Cornet (2), Lieven De Zutter (1).

(1) Ghent University, Faculty of Veterinary Medicine, Department of Veterinary Public Health and Food Safety, Salisburylaan 133, 9820 Merelbeke, Belgium.

(2) Scientific Institute of Public Health, J. Wytsmanstraat 14, 1050 Brussels, Belgium

15 In order to examine if microbiological inhibition tests commonly used for detection of 16 antibiotic residues are suited for routine screening for residues from all commonly used 17 quinolones, the limits of detection (LOD) of 10 different quinolones and fluoroquinolones 18 were determined. Two media were tested, one at $\mathrm{pH} 6$ and one at $\mathrm{pH} 8$, and each was 19 seeded with one of the following test strains: Bacillus subtilis, Escherichia coli, or 20 Bacillus cereus. The LODs of the 10 substances were highest on the plates seeded with $B$.

21 cereus, intended for selective detection of tetracycline residues. The patterns of the zones 22 on the 4 other plates differed for the targeted quinolones: flumequine and oxolinic acid 23 were detected at lower concentrations at $\mathrm{pH} \mathrm{6,} \mathrm{while} \mathrm{the} \mathrm{LODs} \mathrm{of} \mathrm{ciprofloxacin,}$ 24 enrofloxacin, danofloxacin, marbofloxacin, sarafloxacin and norfloxacin were lower at $25 \mathrm{pH}$ 8. Nine of the 10 quinolones were detected easier with E. coli, but the LOD of 26 difloxacin was lower with $B$. subtilis. Finally, the three most sensitive media were 27 selected, and fluid from chicken meat spiked with 8 quinolones, at or around MRL levels 28 was analysed on each of the plates. The plate seeded with E. coli at $\mathrm{pH} 8$ detected 5 of the 298 quinolones at levels of interest, but an additional E. coli plate at PH 6 was necessary for 30 detection of flumequine in species other than poultry and fish. None of the plates detected 
1 oxolinic acid and difloxacin at levels equal to the maximum residue limit (MRL) in

2 muscle tissue.

4 Keywords: fluoroquinolone, quinolone, antibiotics, residues, screening, meat, agar 5 diffusion tests.

6

\section{$7 \quad$ Introduction}

9 Quinolones are a group of synthetic molecules used as antibacterials in human and animal 10 medicine. Nalidixic acid, the first quinolone used as an antibacterial agent, was 11 introduced in 1962. During the following decades, different chemical alterations were 12 made to the quinolone nucleus, resulting in lower toxicity, enhanced antibacterial activity 13 and more advantageous pharmacokinetic properties (Papich and Riviere, 2001).

15 Several quinolones have been approved for use in food producing animals. In poultry, 16 they are almost always administered via the drinking water. During the last decades 17 however, fluoroquinolone resistance in zoonotic pathogens such as Campylobacter has 18 become more frequent, and therefore the approval for veterinary use has been criticized 19 (Pérez-Trallero and Zigorraga, 1995; Nachamkin et al., 2002). Maximum residue limits 20 (MRL) have been established in the European Community for seven quinolones: 21 danofloxacin, difloxacin, enrofloxacin, flumequine, marbofloxacin, oxolinic acid and 22 sarafloxacin. Ciprofloxacin, a quinolone approved for use in human medicine, is also an 23 active metabolite of enrofloxacin, and the sum of both the parent molecule and metabolite 24 should be measured instead of enrofloxacin alone. Sarafloxacin does not have an MRL 25 for muscle tissue in poultry, only in liver and "skin + fat", while the MRL in "muscle + 26 skin in natural proportions" in salmonidae is $30 \mu \mathrm{g} \mathrm{kg}^{-1}$ (Anonymous, 2004; Van Hoof et 27 al. 2005). The six other products have MRLs in muscle ranging from $100 \mu \mathrm{g} \mathrm{kg}^{-1}$ to $600 \mu \mathrm{g}$ $28 \mathrm{~kg}^{-1}$, depending on the quinolone and on the animal species. A summary of the MRLs in 29 muscle tissue from different food producing species can be found in Table 1. 
1 [Insert Table 1 about here]

3 Animal tissues are often screened for antibacterials using microbiological inhibition tests.

4 They rely on the common property of all antibacterials, namely inhibition of growth of 5 susceptible bacteria, and are thus considered as not specific. In practice, however, such

6 tests do not detect residues belonging to all groups of antibiotics, mainly because the 7 different test strains are not equally sensitive to sufficiently low levels of each antibiotic 8 (Korsrud et al., 1998). For example, a widely used method based on inhibition of growth 9 of Bacillus stearothermophilus is able to detect several sulfonamides at levels near to the 10 MRL, $\beta$-lactam antibiotics are detected at levels far below the MRL, but the test is not 11 suited for quinolones (Stead et al. 2005). Methods based on the inhibition of Bacillus 12 subtilis are also intended for detection of different antibiotics and find lower levels of the 13 quinolones, but methods using Escherichia coli as a test strain are considered the best 14 choice for this antibiotic family (Ellerbroek 1991; Okerman et al. 2001; Gaudin et al. 15 2004).

17 However, few data obtained with quinolone and fluoroquinolone antibiotics on B. subtilis 18 and E. coli seeded media have been published. These methods were first considered for 19 analysis of flumequine, enrofloxacin and ciprofloxacin in meat, (Ellerbroek 1991, 20 Okerman et al. 2001).More recently, Gaudin et al. (2004) developed a discriminating 21 method for 66 antibiotics, including 5 quinolones, in milk. They used 5 different media, 22 and found that the E. coli seeded plate at $\mathrm{pH} 8$ was suited for enrofloxacin, ciprofloxacin, 23 danofloxacin and marbofloxacin, while flumequine was not detected at MRL levels on 24 any of the plates. Media seeded with E. coli or with B. subtilis at pH6 were not included 25 in the screening method.

27 In the present study, test media of $\mathrm{pH} 6$ or $\mathrm{pH} 8$, seeded with $B$. subtilis or $E$. coli, were 28 compared for detection of quinolone and fluoroquinolone antibiotics. The LODs of the 10 29 substances were also determined with media seeded with Bacillus cereus at both $\mathrm{pH}$ 30 levels, because this test strain is used for detection and presumptive identification of 
1 tetracyclines (Okerman et al. 2001, Gaudin et al. 2004). We found that the quinolones did 2 not behave in a similar way, and that the inhibition patterns of some of them were 3 different from the others, making a presumptive identification of the quinolone antibiotic 4 family more complicated. The practical consequences of these findings are discussed. 5

\section{Materials and Methods}

\section{$8 \quad$ Media and strains}

9 Six different test media were prepared. Antibiotic Test Agar pH6 and Antibiotic Test 10 Agar pH8 (Merck, Darmstadt, Germany) were constituted and sterilized as prescribed by 11 the manufacturer, and cooled to $45-50^{\circ} \mathrm{C}$. One of the following test bacteria was added: $B$. 12 subtilis BGA spore suspension (Merck, 1.10649.0001), B. cereus spore suspension 13 (Difco, Detroit, USA; not available any more), or a suspension of E. coli strain Bayer 14 14 (kindly provided by Bayer, Leverkusen, Germany) prepared as described in a previous 15 paper (Okerman et al. 2001). The final concentration of the test strains was in each case 16 between10E4 - 10E5 colony forming units per mL medium. 90mm plates were filled 17 either with $5 \mathrm{~mL}$ of the seeded media, for determination of LODs of quinolones dissolved 18 in $10 \mu \mathrm{l}$ water, or with $14 \mathrm{~mL}$, for analysis of $100 \mu \mathrm{L}$ of spiked meat fluid. Plates were 19 stored before use at $4^{\circ} \mathrm{C}$ for 7 days maximum.

\section{Antibiotics}

22 The antibiotics enrofloxacin, ciprofloxacin, and nalidixic acid were obtained from ICN 23 biomedicals (Irvine, USA), flumequine, norfloxacin and oxolinic acid from Sigma (St 24 Louis, USA), marbofloxacin from Vetoquinol (Lure, France), sarafloxacin from Solvay 25 Duphar (Weesp, The Netherlands), difloxacin from Fort Dodge Animal Health (Naarden, 26 the Netherlands), and danofloxacin from Pfizer (Sandwich, U.K.). Stock solutions of 1 $27 \mathrm{mg} \mathrm{mL}^{-1}$ were prepared in $0.1 \mathrm{~N} \mathrm{NaOH}$, divided into aliquots, frozen and kept at $-20^{\circ} \mathrm{C}$ 28 for maximum 2 months.

\section{Determination of LODs}


1 After thawing, the stock solutions were diluted in distilled water. Series of twofold 2 concentrations were tested, from $8000 \mathrm{ng} \mathrm{mL}^{-1}$ to $62.5 \mathrm{ng} \mathrm{mL}^{-1}$, when necessary. Paper 3 disks with a diameter of $6 \mathrm{~mm}$ were laid upon the thin agar layers, and impregnated with $410 \mu \mathrm{L}$ of the appropriate dilutions. Each dilution that produced zones between $6 \mathrm{~mm}$ (the 5 diameter of the paper disk) and $25 \mathrm{~mm}$ was tested fourfold on each of the 6 media. The 6 plates were incubated for $16-20 \mathrm{~h}$ at $30^{\circ} \mathrm{C}$, and then controlled for zones of complete 7 inhibition. The lowest concentration that gave at least 3 zones of $12 \mathrm{~mm}$ diameter around 8 the 4 paper disks, paper disk included, was considered as the LOD, and was expressed as 9 ng per paper disk.

11 Preparation and analysis of fortified meat fluid

12 Frozen fillets from chickens that had not been treated with antibiotics were thawed at 13 room temperature in a clean recipient, and the fluid was collected in tubes. $10 \%$ of a 14 solution of one of the quinolones enrofloxacin, ciprofloxacin, flumequine, marbofloxacin, 15 danofloxacin, difloxacin, sarafloxacin or oxolinic acid were added to $90 \%$ of this meat 16 fluid. The final concentrations expressed in $\mathrm{ng}$ per $\mathrm{mL}$ meat fluid were equal to their 17 respective MRLs in $\mu \mathrm{g} \mathrm{kg}^{-1}$. When necessary, concentrations corresponding with the 18 double of the MRLs were also tested. Holes with a diameter of $8 \mathrm{~mm}$ were punched into 19 the $2 \mathrm{~mm}$ agar layer and the wells were filled with $100 \mu \mathrm{L}$ of the artificially contaminated 20 meat fluid. The plates were incubated overnight at $30^{\circ} \mathrm{C}$. The diameters of the rings of 21 inhibition, from the edges of the wells till the first visible colonies, were measured. At 22 least 20 observations were done, and they were obtained on two or three different 23 occasions.

\section{Results}

26 Table 2 shows the LODs of the 10 quinolones and fluoroquinolones tested on the 6 27 different media. All but one of the 10 substances were better detected with E. coli than 28 with $B$. subtilis. The LOD of difloxacin was two to four times higher with $E$. coli than 29 with B. subtilis, at $\mathrm{pH} 6$ as well as at $\mathrm{pH} 8$. Plates seeded with $B$. cereus were least 30 sensitive to the 10 quinolones tested. 
[Insert Table 2 about here]

4 The pH did not markedly influence the detection of marbofloxacin, while sarafloxacin, 5 norfloxacin, enrofloxacin, danofloxacin and ciprofloxacin were optimally detected at $6 \mathrm{pH} 8$. On the other hand, difloxacin, oxolinic acid and especially flumequine had lower 7 LODs on the pH 6 media. Nalidixic acid was not detected on any of the plates at levels 8 lower than 40 ng per disk.

10 Figures 1 and 2 illustrate a comparison between the two plates seeded with E. coli, and 11 between the $E$. coli $\mathrm{pH} 8$ plate and the $B$. subtilis $\mathrm{pH} 6$ plate. The lines between the LODs 12 of the different quinolones are not concentric on these figures. This means that an 13 optimal $\mathrm{pH}$, that detects all quinolones at the lowest concentration possible, could not be 14 determined, and that neither of the two microorganisms is more sensitive to all 15 quinolones.

[Insert figure 1 about here]

[Insert figure 2 about here]

21 The results of the artificially contaminated chicken fluid are presented in Table 3. Plates 22 seeded with B. subtilis did not detect any of the quinolones at MRL levels in 100 $\mu 1$ fluid 23 from chicken muscle. Difloxacin, however, was found at twice the MRL on the pH6 24 medium seeded with $B$. subtilis ( $86 \%$ positive results), while this concentration was not 25 detected on the plates seeded with E. coli.

27 Best results were obtained on $E$. coli plates for most quinolones: the pH8 medium 28 detected enrofloxacin, ciprofloxacin, danofloxacin and flumequin at MRL levels for 29 poultry, and enrofloxacin, ciprofloxacin, danofloxacin and marbofloxacin at MRL levels 30 for porcine and bovine muscle. The pH6 medium detected flumequine at 400ng per $\mathrm{mL}$ 
1 fluid, corresponding with the MRL for poultry, and in $90 \%$ of the cases at 200ng per mL,

2 corresponding with the MRL for slaughter animals other than poultry and fish.

3 [Insert Table 3 about here]

4

5 Discussion

6

7 Two important conclusions can be drawn from he results obtained with aqueous solutions

8 of quinolones as well as with chicken fluid, spiked with quinolones at levels

9 corresponding with the MRL:

11 1. The detection capability of the plates differs depending on the quinolone,

12 2. Discrimination between quinolones and other antibiotic families is not possible when

13 only plates seeded with E. coli and B. subtilis are used.

15 The implications of these findings in the field of residue testing can be described as 16 follows.

18 Choice of a plate capable to detect quinolone antibiotics

19 The LODs of the ten quinolones were highest on plates seeded with B. cereus. But, the 20 determination of LODs diluted in distilled water demonstrated different sensitivities of 21 the quinolones to E. coli and B. subtilis. Moreover, the optimal $\mathrm{pH}$ was dependent on the 22 substance. This means that none of the plates can be selected as best choice. Indeed, In 23 order to obtain the lowest LODs of the seven quinolones, a combination of three plates 24 was needed: two seeded with $E$. coli, at $\mathrm{pH} 6$ and at $\mathrm{pH} 8$, and one seeded with $B$. subtilis, 25 at $\mathrm{pH} 6$. The $\mathrm{pH} 8$ plate seeded with E. coli detected enrofloxacin, ciprofloxacin, 26 flumequine, and danofloxacin in meat fluid spiked at levels equal to the MRL in chicken 27 muscle. Marbofloxacin does not have a MRL for poultry, but levels corresponding with 28 the MRL for bovine and porcine muscle tissue, $150 \mu \mathrm{g} \mathrm{kg}^{-1}$, were detected easily. 29 Flumequine however, with a MRL of $200 \mu \mathrm{g} \mathrm{kg}^{-1}$ in all animal species other than fish and 30 poultry, was only detected at that level at $\mathrm{pH}$, 
2 Only three approved quinolones and fluoroquinolones were not detected at sufficiently 3 low levels with a combination of agar diffusion tests: difloxacin, sarafloxacin and 4 oxolinic acid. The pharmacokinetic properties of difloxacin and sarafloxacin suggest that 5 residues in muscle are not at issue, because only in the first days or hours after treatment

6 very low levels of these substances can be found. Moreover, difloxacin is partly 7 metabolised into sarafloxacin in vivo (Barrón et al. 2002). Sarafloxacin does not have a 8 MRL in muscle from poultry or from other species except fish, where the MRL relates to 9 skin + muscle in normal proportions. Residues of difloxacin and sarafloxacin remain 10 present for a longer time in liver tissue or in poultry skin and fat. On the other hand, high 11 residue levels occur in all tissues, including muscles, after oral administration of oxolinic 12 acid to broilers.

14 Quinolones may also be detected with immunological or with chromatographic methods, 15 such as liquid chromatography coupled to mass spectrometry (Hernandez-Arteseros et al. 16 2002). Chromatographic methods are particularly intended for identification and 17 quantification of separate compounds, and are not considered first choice for screening 18 large numbers of samples, most of which are not likely to contain any residues. 19 Immunological methods are preferred for screening and post screening, as they are 20 specific for one group. Still, these methods are much more labour-intensive and 21 expensive than the classical inhibitor tests. Enzyme immuno assay (EIA) kits have been 22 commercialised by different manufacturers for detection of quinolone residues (for 23 example, Euro-diagnostica, Arnhem, the Netherlands; Randox, Crumlin, Co Antrim, 24 Northern Ireland; CER, Marloie, Belgium). Cross reactivities between different 25 quinolones are however not optimal in most cases. Especially the case of flumequine is 26 problematic. This substance which is used more often to broilers in Belgium and the 27 Netherlands than any other quinolone or fluoroquinolone (Okerman et al. 2004), is not 28 detected with most commercial tests, unless the tests are selective for this antibiotic. The 29 use of two EIA kits for detection of one group is expensive, compared to microbiological 30 screening or even chromatographic detection. 
2 Discrimination between quinolones and other antibiotic families

3 Microbiological screening of slaughter animals and poultry for antibiotic residues in

4 general requires the use of more than one medium and/or test bacterium (Korsrud et

5 al.1998). Profit can be taken from this apparent complication to attempt presumptive

6 identifications (Okerman et al. 2001). These provide guidance in the selection of

7 appropriate confirmatory tests. A B. subtilis- seeded medium at pH6 can be used for

8 tetracyclines (Okerman et al. 2004), while the present results suggest the use of a pH8

9 medium seeded with E. coli for detection of as many quinolones as possible. However,

10 the fact that some quinolones are better detected with B. subtilis seeded pH6 media has

11 consequences on the presumptive identification of antibiotic families in inhibitor positive

12 samples. It is expected that samples contaminated with tetracyclines will produce larger

13 zones on the B. subtilis seeded pH6 medium, and samples contaminated with quinolones

14 on E. coli seeded pH8 medium (Gaudin et al. 2004). But this is not true for flumequine,

15 difloxacin and sarafloxacin (figure 2). Although the STAR method, as described by

16 Gaudin et al. (2004), requires an incubation of the E. coli plate at $37^{\circ} \mathrm{C}$, while in the

17 present investigation all incubations were carried out at $30^{\circ} \mathrm{C}$, it is highly improbable that

18 the inhibition patterns of quinolones will change at a higher temperature. Media seeded

19 with B. cereus, on the other hand, are applied for the presumptive identification of

20 tetracyclines, and the high LODs that we found earlier with enrofloxacin, ciprofloxacin

21 and flumequine on these plates were now confirmed with the other quinolones.

22 Unfortunately, the commercial B. cereus spore suspension is no more available, and has

23 to be prepared with own techniques, which is not convenient for many routine residue

24 labs. The B. cereus based method can be replaced by a group specific test for

25 tetracyclines, such as a receptor assay (Okerman et al. 2004).

27 Practical conclusions

28 The addition of a pH8 medium seeded with E. coli Bayer 14 in a microbiological 29 screening system allows the detection of 5 fluoroquinolones at MRL levels in muscle 30 tissue from poultry. A second plate with a pH6 medium, seeded with the same test 
1 bacterium, is necessary to detect flumequine at MRL levels in species other than poultry

2 and fish. All samples producing zones on one or two of the E. coli plates should be

3 considered as suspect for the presence of quinolones. Samples producing zones on a $\mathrm{pH} 6$

4 medium seeded with $B$. subtilis are most likely to contain tetracyclines, but the presence

5 of fluoroquinolones cannot be excluded.

6

7 Acknowledgement.

8

9 The authors thank Fanny Wallaert and Sandra Vangeenberghe for their excellent technical 10 assistance. 


\begin{abstract}
1 References
2

3 Anonymous, 2004, Consolidated version of the Annexes I to IV of Council Regulation $\mathrm{n}^{\circ}$

$42377 / 90$. Updated up to 22.12.2004. http://pharmacos.eudra.org/F2/mrlconspdef

$5 \quad$ accessed 2006 May 29.

6 Barrón D., Jimenez-Lozano E., Bailac S., Barbosa J., 2002. Determination of difloxacin

7 and sarafloxacin in chicken muscle using solid-phase extraction and capillary

8 electrophoresis. Journal of Chromatography B., 313-319.

9 Ellerbroek, L. 1991. Zum mikrobiologischen Nachweis der Chinolonsäurederivate

10 Enrofloxacin, Ciprofloxacin und Flumequine. Fleischwirtschaft 71, 187-189.

11 European Agency for the Evaluation of Medicinal Products (EMEA). Committee for

12 Veterinary Medicinal Products. Summary reports of difloxacin, oxolinic acid and

13 difloxacin. Available from: http://www.emea.eu.int/pdfs/vet/mrls/ Accessed 2006

$14 \quad$ May 29.
\end{abstract}

15 Hernandez-Arteseros J.A., Barbosa J., Compañó R., Prat M.D. (2002). Analysis of 16 quinolone residues in edible animal products. Journal of Chromatography A., 945, $17 \quad 1-24$.

18 Korsrud, G.O., Boison, J.O., Nouws, J.F.M. and Macneil, J.D., 1998, Bacterial inhibition

19 tests used to screen for antimicrobial drug residues in slaughtered animals. Journal

Okerman L., Van Hoof J., Devriese L., 2004. Keuze van geschikte screeningstesten voor 26 of AOAC International 81, 21-24.

Okerman L., Croubels S., De Baere S., Van Hoof J., De Backer P., and De Brabander H., 2001. Inhibition tests for detection and presumptive identification of tetracyclines, beta-lactam antibiotics and quinolones in poultry meat. Food Additives and Contaminants 18, 385-393. Tijdschrift 73, 90-102.

Papich M.G. and Riviere J.E., 2001. Fluoroquinolone antimicrobial drugs. In: Adam R. (Editor), Veterinary Pharmacology and Therapeutics. Iowa State University Press, Ames. 
1 Nachamkin I., Ung H., Li M., 2002. Increasing fluoroquinolone resistance in 2 Campylobacter jejuni, Pennsylvania, USA, 1982-2001. Emerging Infectious 3 Diseases 12: 1501-1503.

4 Stead S., Sharman M., Tarbin J.A., Gibson E., Richmond S., Stark J., and Geijp E., 2004. 5 Meeting maximum residue limits: an improved screening technique for the rapid 6 detection of antimicrobial residues in animal food products. Food Additives and 7 Contaminants 21, 216-221.

8 Pérez-Trallero E., Zigorraga C., 1995. Resistance to antimicrobial agents as a public 9 health problem: importance of the use of antibiotics in animals. International 10 Journal of Antimicrobial Agents 6, 59-63.

11 Van Hoof N., De Wasch K., Okerman L., Reybroeck W., Poelmans S., Noppe H., De 12 Brabander H., 2005. Validation of a liquid chromatography-tandem mass 13 spectrometric method for the quantitation of eight quinolones in bovine muscle, 14 milk and aquacultured products. Analytica chimica acta 529, 265-272. 
Table 1. MRLs $\left(\mu \mathrm{g} \mathrm{kg}^{-1}\right)$ of quinolones in muscle tissue of different food producing animals.

\begin{tabular}{|c|c|c|c|c|c|c|c|}
\hline & Bovine & $\begin{array}{l}\text { Ovine, } \\
\text { caprine }\end{array}$ & Porcine & Poultry & Rabbits & Fish & $\begin{array}{l}\text { Other } \\
\text { species }\end{array}$ \\
\hline Danofloxacin & 200 & 200 & 100 & 200 & 100 & 100 & 100 \\
\hline Difloxacin & 400 & 400 & 400 & 300 & 300 & 300 & 300 \\
\hline $\begin{array}{l}\text { Enro + } \\
\text { ciprofloxacin }\end{array}$ & 100 & 100 & 100 & 100 & 100 & 100 & 100 \\
\hline Flumequine & 200 & 200 & 200 & 400 & 200 & 600 & 200 \\
\hline Marbofloxacin & 150 & & 150 & & & & \\
\hline Sarafloxacin & & & & & & $30 *$ & \\
\hline Oxolinic acid & & & 100 & 100 & & 100 & \\
\hline
\end{tabular}

* MRL refers only to salmonidae, muscle and skin in natural proportions 
Table 2. LODs (ng/paper disk) of 10 quinolones dissolved in water on 6 media.

\begin{tabular}{lcccccc} 
& \multicolumn{2}{c}{ E. coli Bayer 14} & \multicolumn{2}{c}{ B. subtilis BGA } & \multicolumn{2}{c}{ B. cereus } \\
& $\mathrm{pH} 6$ & $\mathrm{pH} 8$ & $\mathrm{pH} 6$ & $\mathrm{pH} 8$ & $\mathrm{pH} 6$ & $\mathrm{pH} 8$ \\
Enrofloxacin & 1.25 & 0.625 & 20 & 10 & $>40$ & 40 \\
Ciprofloxacin & 2.5 & 1.25 & 20 & 10 & 40 & 40 \\
Difloxacin & 40 & $>40$ & 10 & 20 & $>40$ & $>40$ \\
Flumequine & 5 & 40 & 20 & $>40$ & $>40$ & $>40$ \\
Sarafloxacin & 20 & 5 & 20 & 10 & $>40$ & 40 \\
Marbofloxacin & 2.5 & 2.5 & 10 & 10 & $>40$ & 40 \\
Norfloxacin & 10 & 5 & 40 & 40 & $>40$ & $>40$ \\
Danofloxacin & 5 & 1.25 & 10 & 2.5 & $>40$ & 40 \\
Nalidixic acid & 40 & $>40$ & $>40$ & $>40$ & $>40$ & $>40$ \\
Oxolinic acid & 5 & 20 & 10 & $>40$ & 40 & $>40$ \\
\hline
\end{tabular}


2

3

4

5

6

7

8

9

10

11

12

13

14

15

16

17

18

19

20

21

22

23

Table 3. Detection of 8 quinolones in fluid from chicken muscle spiked at levels of interest with 4 agar diffusion tests.

\begin{tabular}{lccccc}
\hline & & \multicolumn{3}{c}{ Range of zones (number detected/number analysed) } \\
\cline { 3 - 6 } & & E. coli $\mathrm{pH6}$ & E. coli $\mathrm{pH} 8$ & B. subtilis $\mathrm{pH6}$ & B. subtilis $\mathrm{pH} 8$ \\
\cline { 3 - 6 } Enrofloxacin & $100 \mathrm{ng} \mathrm{mL}^{-1}$ & $\mathrm{ND}$ & $3.1-5.1(25 / 25)$ & $\mathrm{ND}$ & $\mathrm{ND}$ \\
Ciprofloxacin & $100 \mathrm{ng} \mathrm{mL}^{-1}$ & $1.2-6.3(25 / 25)$ & $4.7-5.5(25 / 25)$ & $\mathrm{ND}$ & $\mathrm{ND}$ \\
Difloxacin & $300 \mathrm{ng} \mathrm{mL}^{-1}$ & $\mathrm{ND}$ & $\mathrm{ND}$ & $\mathrm{ND}$ & $\mathrm{ND}$ \\
Difloxacin & $600 \mathrm{ng} \mathrm{mL}^{-1}$ & $\mathrm{ND}$ & $\mathrm{ND}$ & $0-5.7(26 / 30)$ & $\mathrm{ND}$ \\
Flumequine & $200 \mathrm{ng} \mathrm{mL}^{-1}$ & $0-1.6(18 / 20)$ & $\mathrm{ND}$ & $\mathrm{ND}$ & $\mathrm{ND}$ \\
Flumequine & $400 \mathrm{ng} \mathrm{mL}^{-1}$ & $1.6-4.1(25 / 25)$ & $1.1-2.4(25 / 25)$ & $\mathrm{ND}$ & $\mathrm{ND}$ \\
Sarafloxacin & $100 \mathrm{ng} \mathrm{mL}^{-1}$ & $\mathrm{ND}$ & $\mathrm{ND}$ & $\mathrm{ND}$ & $\mathrm{ND}$ \\
Sarafloxacin & $200 \mathrm{ng} \mathrm{mL}^{-1}$ & $\mathrm{ND}$ & $0-2.6(10 / 20)$ & $\mathrm{ND}$ & $\mathrm{ND}$ \\
Marbofloxacin & $150 \mathrm{ng} \mathrm{mL}^{-1}$ & $0-5.1(23 / 25)$ & $4.1-5.8(20 / 20)$ & $\mathrm{ND}$ & $\mathrm{ND}$ \\
Danofloxacin & $100 \mathrm{ng} \mathrm{mL}^{-1}$ & $\mathrm{ND}$ & $4.2-5.2(20 / 20)$ & $\mathrm{ND}$ & $\mathrm{ND}$ \\
Danofloxacin & $200 \mathrm{ng} \mathrm{mL}^{-1}$ & $\mathrm{ND}$ & $4.5-7.5(25 / 25)$ & $\mathrm{ND}$ & $0-4,3(19 / 20)$ \\
Oxolinic acid & $100 \mathrm{ng} \mathrm{mL}^{-1}$ & $\mathrm{ND}$ & $\mathrm{ND}$ & $\mathrm{ND}$ & $\mathrm{ND}$ \\
Oxolinic acid & $200 \mathrm{ng} \mathrm{mL}^{-1}$ & $0-3.7(19 / 20)$ & $0.2-2.5(25 / 25)$ & $\mathrm{ND}$ & $\mathrm{ND}$ \\
\hline
\end{tabular}

$* \mathrm{ND}=$ not detected: no zones were observed in more than $50 \%$ of the cases. 
Figure 1

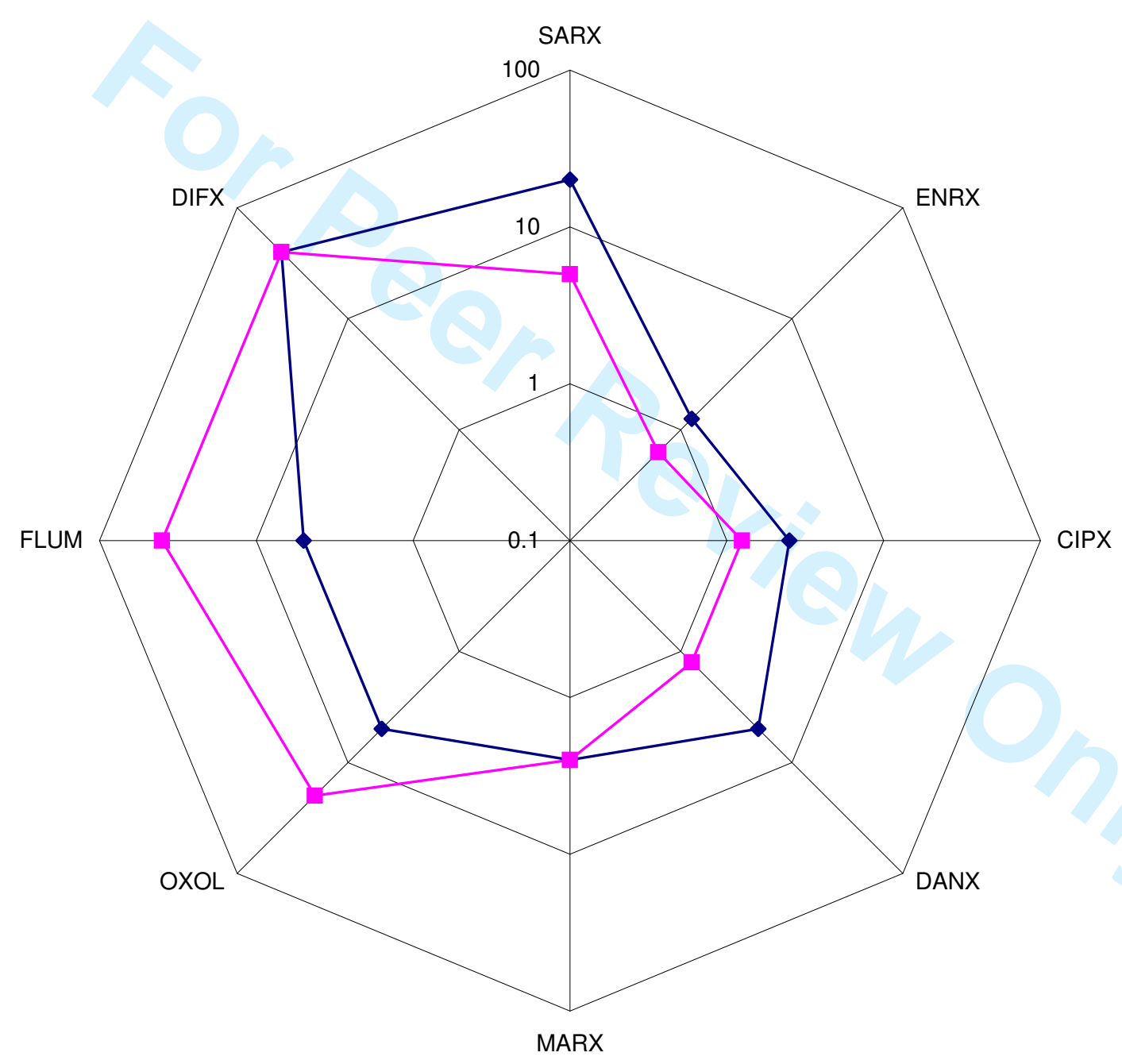


Figure 2

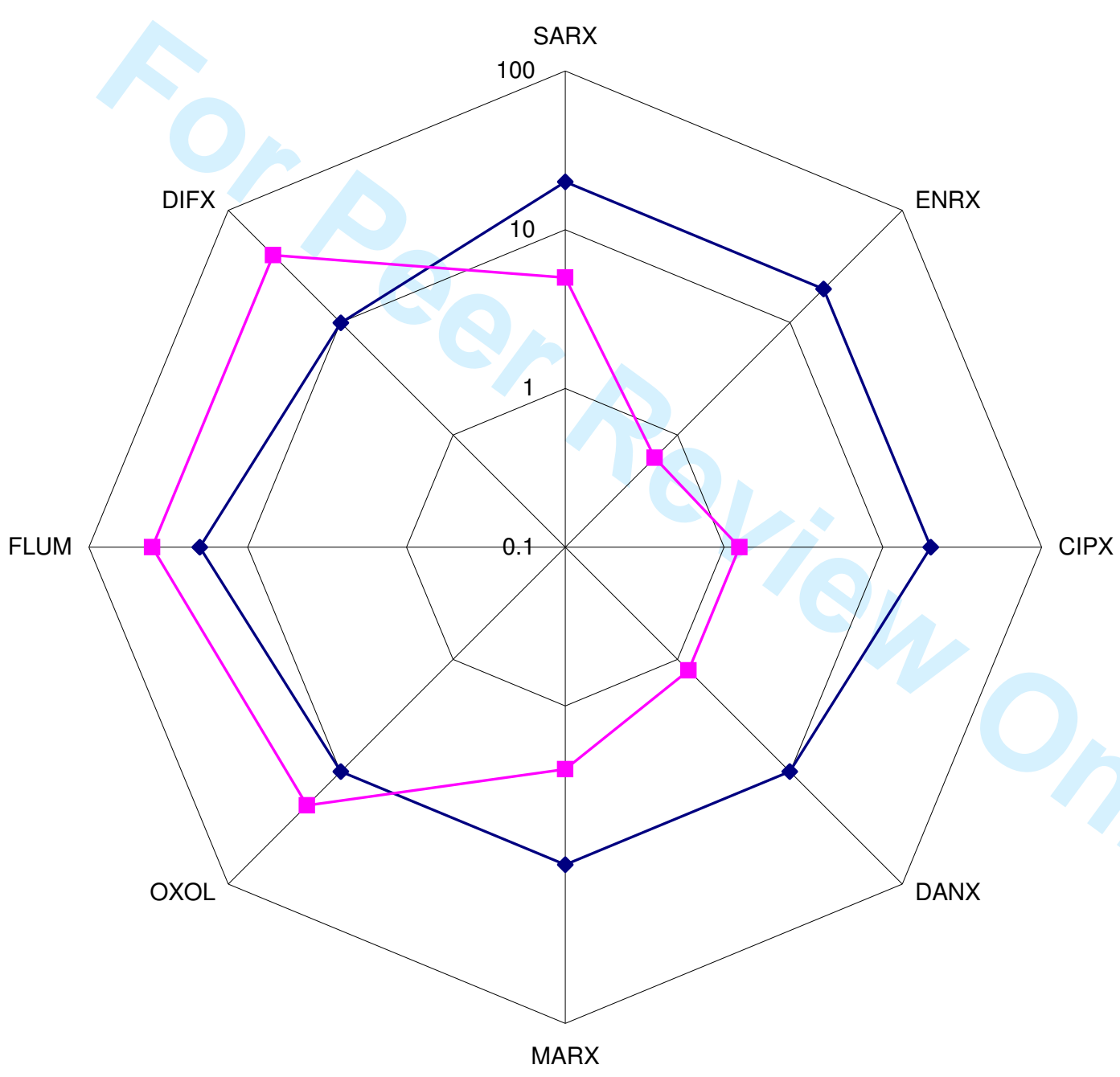


1

2

3

4

5

6

7

8

9

10

11

12

13

14

15

16

17

18

19

20

21

22

23

24

25

26

27

28

29

30

31

32

33

34

35

36

37

38

39

40

41

42

43

44

45

46

47

48

49

50

51

52

53

54

55

56

57

58

59

60

$\begin{array}{rr}\text { E. coli } \mathrm{pH} 6 & \text { E. coli } \mathrm{pH} 8 \\ 20 & 5 \\ 1.25 & 0.625 \\ 2.5 & 1.25 \\ 5 & 1.25 \\ 2.5 & 2.5 \\ 5 & 20 \\ 5 & 40 \\ 40 & 40\end{array}$

$\begin{array}{lr} & \text { B.subtilis } \mathrm{pH} 6 \\ \text { SARX } & 20 \\ \text { ENRX } & 20 \\ \text { CIPX } & 20 \\ \text { DANX } & 10 \\ \text { MARX } & 10 \\ \text { OXOL } & 10 \\ \text { FLUM } & 20 \\ \text { DIFX } & 10\end{array}$




$\begin{array}{rr}\text { E. coli pH8 } & \text { MRL } \\ 5 & 3 \\ 0.625 & 10 \\ 1.25 & 10 \\ 1.25 & 10 \\ 2.5 & 15 \\ 20 & 10 \\ 40 & 20 \\ 40 & 30\end{array}$

